\title{
TYPES OF DERIVATIONAL AFFIXES IN NEW IDEA MAGAZINE: A MORPHOLOGICAL ANALYSIS
}

\author{
Ni Kadek Chandra Dwiyanti ${ }^{1}$, Putu Devi Maharani ${ }^{2}$, IB Gde Nova \\ Winartha $^{3}$ \\ Mahasaraswati Denpasar University, Indonesia ${ }^{123}$ \\ chandradwiyanti74@gmail.com,devmaharani86@gmail.com, \\ gusdnova@gmail.com
}

Journal History

Submitted 30th December 2021

Revised 20th January 2022

Accepted 23rd January 2022

Published 24th January 2022

Keywords:

derivational, affixes, types

\begin{abstract}
This study was aimed to identify the derivational affixes that can be found in "New Idea"magazine. Specifically, this study was focused on analyzing the types and the process of derivational affixes that were found in the data source. This study used qualitative descriptive method to analyze the data. The data were analyzed based on the theory proposed by Katamba (1993) to solve the problem which about the types of derivational affixes. Theory that proposed by Rochelle Lieber (2009) was used to solve the problem about the morphological process of derivational affixes. This study found 427 data that contains derivational affixes. Derivational prefixes were found in 52 data with percentage $12 \%$ such as prefix in-, un-, dis- , re-, ex-, en-, and pre-. Then, derivational suffixes were found in 375 data with percentage $88 \%$ such as suffix-hood, -ship,-ness, -ity, -ment, -less, -ful, $-i c,-a l,-e r,-l y,-i o n,-i s h$,-ing and -ed. This study concluded that derivational suffix-ly was the most dominant type of derivational affixes that found in "New Idea"magazine.
\end{abstract}




\section{INTRODUCTION}

Language is very important for us as a tool of communication; people can deliver the language by spoken or written. Without language we cannot express our feelings, ideas, thoughts, and opinions. Aside of mastering their mother-tongues, they also have to understand another language in order to communicate with other people easier. Therefore, language and people cannot be separated. The language is often viewed as a vehicle of thought, a system of expression that mediates the transfer of thought from one person to another (Finegan, 2008). The fundamental functions of language are derived from the basic components of any interaction, such as the speaker, the addressee, and the message (Lestari, 2021)

The science of language is called linguistics, the role of linguistics includes morphology which means, it deals with the structure of words. In this case, Lieber (2009) stated that the study of word formation in linguistics is called morphology, besides that in morphology there is also the way a word is created and also how the formation of words varies according to how the words are used in a sentence. Until the 19th century, morphology did not emerge as a sub-branch where morphology was the study of the internal structure of words (Katamba, 1993). One of the important knowledge that must be learned by people is about words, although a word looks so simple but the word has a broad meaning and can be divided into several parts. Therefore, it is very important to study the context of the word in order to have broad insight and have good and proper English skills. The smallest part of a word is called as morpheme which is formed from a combination of several components. Morphemes can be divided into two, namely free morphemes and bound morphemes. A morpheme that can stand alone and has its own meaning as a word is called a free morpheme, while a morpheme that cannot stand alone and requires another morpheme to create a meaning in a word is called a bound morpheme.

According to Katamba (1993), a word has an internal structure and also has several elements to form a word. These structures consist of roots, stems, bases and also affixes. The root is the essence of a word that cannot be reduced without any affixes attached to it. Stem is a word structure found in inflectional affixes. The base will appear when there are additional affixes to a word either inflectionally or derivationally. Affix is a morpheme that only appears on the stem, root or base. There are three structures that can be categorized as free, namely roots, stems and bases because they have their own meaning as a word and can stand alone. Affixes are categorized as related morphemes because affixes require base words to complete the existence of affixes so as to create a meaning in a word. An affix can be divided into three, namely: Prefix, Infix, and Suffix. Prefix is an affix that attached before root. Infix is an affix that inserted 
into the root itself. Suffix is an affix that attach after the root. There are two common processes in English Morphology, they are Derivational and Inflectional. According to McCarthy (2002), derivational processes unlike inflection, they can change the word class of the bases to which they apply. The differences between derivational and inflectional are changing the word class and meaning for derivational such as: un-, -ment, -al, -er, ize, -il, -ation, -ly, -dom, ab-, -less, and -ism. Meanwhile, inflectional are changes the quantity or tenses such as: -s, -ing, -ed, and -en.

This study used magazine as a data source. Magazines are news collections that contain colourful images. Magazine is published regularly and contains sports news, political news, advertisement news, social life. By reading magazine can help to fine new vocabulary, find news, and improve the pronunciation in reading skill. In magazine there are some words that use derivational affixes. This study is focused on analyzing derivational affixes which found in New Idea magazine which consists of 92 pages.

In addition, there are some words classes are change by derivational affixes such as derivational verb, derivational noun, derivational adjective and derivational adverb. In other hand, the function of derivational affixes is not only to create a word with changing a word class meanwhile recategorize each word based on affixes that used. The example above brings the idea that it was really needed to analyze the type of derivational affixes in a magazine entitled "New Idea".

\section{METHODS}

The data of this study are obtained derivational affixes which found in "New Idea" magazine. "New Idea" magazine was published on October, 21st 2019 which consist of 92 pages, in this magazine there are articles such as sport, advertisement, crime, scandal, food, puzzle, and love story. "New Idea" magazine is chosen as the data source because, aside of "New Idea" magazine being a fairly popular magazine, the appearance of this magazine is also interesting. There are many articles containing derivational affixes that can support this article as the data source of this research. Furthermore, before the data is presented using informal and formal data, the data is collected using the observation method and then processed to analyze the data through a qualitative descriptive method.

\section{RESULTS}

\section{RESULTS AND DISCUSSION}

The finding of this study shows that derivational affixes are indeed performed in "New Idea" magazine which publish on October, 21 2019. The table of data finding is presented below. 
Table 1 Types of Derivational Affixes Found in "New Idea" Magazine

\begin{tabular}{|c|c|c|c|}
\hline Derivational Affixes & Frequency & Total Data & Percentage \\
\hline Derivational Prefix & 7 & 52 & $12 \%$ \\
\hline Derivational Suffix & 15 & 375 & $88 \%$ \\
\hline Total & 22 & 427 & $100 \%$ \\
\hline
\end{tabular}

The table shows the occurences of each type of derivational affixes found in "New Idea" magazine. It can be seen in the table above, the most frequent type that appeared in the data source is derivational suffixes with the percentage of $88 \%$ or 375 data of all derivational affixes data that were found. Meanwhile, the data regarding to derivational prefixes occurred with percentage of $12 \%$ or 52 data.

\section{DISCUSSION}

In this section, the data regarding to derivational affixes found in "New Idea" magazine are analyzed further in order to achieve deeper understanding regarding to the process of dervational affixes. Specifically, several data that used as representative of each type of derivational affixes found in the magazine are presented as follows.

The most dominant type of derivational affixes found in "New Idea" magazine is shown to be derivational suffixes with $88 \%$ or 375 data and the least dominant type is shown to be derivational prefixes with the total of 52 data or $12 \%$. The explanation of the type of derivational affixes together with the morphologial processes that found in the data source are provided as follows.

\section{A. DERIVATIONAL PREFIXES}

This section discussed about the analysis of derivational prefixes found in "New Idea" magazine. This study found some prefixes that occurred in 84 data. They were prefix in-, un-, dis-, re-, ex-, en-, and pre-.

\section{Data 1}

But police were unable to find any real evidence against him, so the case went cold. (New Idea, P.37)

In the data 1 , the word unable (Adj) consist of two morpheme, they are un- (bound morpheme) and able (Adj) (free morpheme). The word unable (Adj) clearly contains affix. Unable (Adj) is derived from the base word able (Adj) that is attached by prefix un-in front of the base. Prefix unfunctions to change the meaning of the base word into the opposite 
meaning in the same word class. Therefore, prefix un- can be categorized as derivational prefix. The base word able (Adj) means the ability to do something, (Oxford Dictionary, 2013). The new word unable (Adj) means inability to do something, (Oxford Dictionary, 2013). The derivational process of the new word unable (Adj) can be seen in the hierarchical structure which represent in tree diagram below:

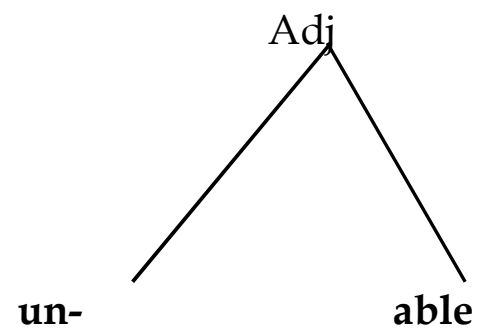

\section{Data 2}

(Adj)

Reheat before placing over patties. (New Idea, P.45)

The word reheat $(\mathrm{V})$ constructed by two morphemes, they are re- which is bound morpheme, and heat $(\mathrm{N})$ which is free morpheme. The prefix reattached to the base word heat $(\mathrm{V})$ its belong to derivational affixes because reheat $(\mathrm{V})$ has changed meaning and the word class. The word heat $(\mathrm{N})$ means a rising and high temperature or the quality of being hot (Oxford Dictionary, 2013). Meanwhile the new word reheat (V) means something that was hot before but experienced a decrease in temperature and then heated again (Oxford Dictionary, 2013). The morphological process can be seen in the tree diagram below:

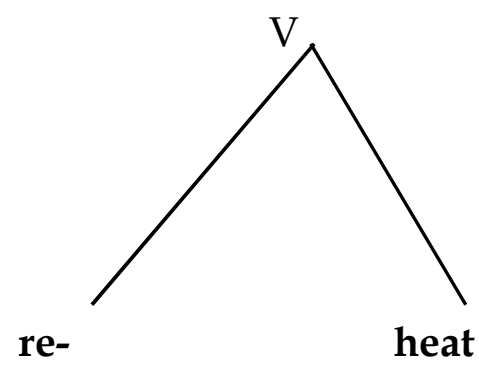

(N)

\section{B. DERIVATIONAL SUFFIXES}

This section discussed about the analysis of derivational suffixes found in "New Idea" magazine. This study found some suffixes that occurred in 375 data. They were suffix -ship, -ness, -ity, -ment, -less, full, -ic, -al, -er, -ly, -ion, -ing, and -ed.

\section{Data 3}

..thank to grandparents for all the choo choos you've built, books 
you've read, song you've sung and endless cuddles you've given. (New Idea, P.92)

In data 3, the word endless (Adj) can be classified as derivational word. There is suffix -less (bound morpheme) that is attached to the base word end $(\mathrm{N})$ (free morpheme) and creates the new word endless (Adj). The suffix-less turns the base end (N) into the opposite meaning. Therefore, suffix -less can be categorized as derivational suffix. The meaning of the base word end $(\mathrm{N})$ is the final part of something such as an activity, a period of time, or a story, (Oxford Dictionary, 2013). The new word endless (Adj) means something that is never end or continuously like an activity, time period, or story. The derivational process of the word endless (Adj) can be seen in the hierarchical structure which represent in tree diagram below:

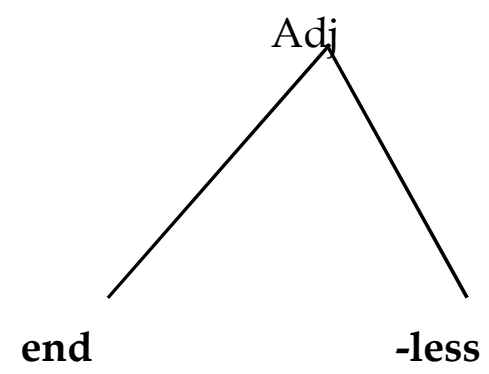

$(\mathrm{N})$

\section{Data 4}

I felt a deep and genuine sadness. (New Idea, P.6)

The word sadness $(\mathrm{N})$ constructed by two morphemes, they are sad (Adj) (free morpheme), and -ness (bound morpheme). The new word sadness $(\mathrm{N})$ is derived from the base word sad (Adj). There is suffix ness which is attached to the base sad (Adj) become sadness (N). Suffix -ness can be categorized as derivational suffix because it can alter the word class of the base. The base word sad (Adj) an emotion that is motivated by loss, feeling unlucky, and helpless, the side effect of many people when sad will feel less enthusiastic and will become more silent (Oxford Dictionary, 2013). Sadness (N) means causing or associated with grief or unhappiness (Oxford Dictionady, 2013). The derivational process of the word sadness $(\mathrm{N})$ can be seen in the hierarchical structure which represents in tree diagram below: 


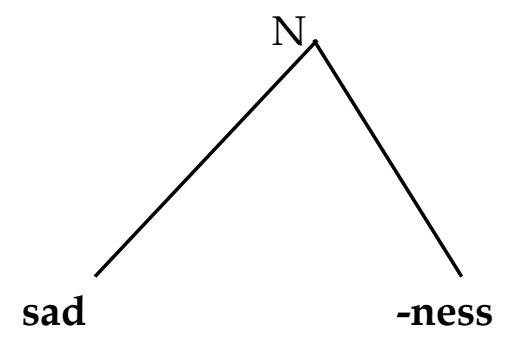

(Adj)

\section{Data 5}

Could he be jealous of his wife's increasing popularity? (New Idea, P.5)

The word popularity $(\mathrm{N})$ in data 5 clearly contains suffix -ity. The base word popular (Adj) (free morpheme) is attached by suffix -ity (bound morpheme) becomes popularity (N). Suffix -ity causes the word class of the base change from adjective to noun. Therefore, suffix -ity can be categorized as derivational suffix. The base word popular (V) means someone who is known and liked by many people (Oxford Dictionary, 2013). Then, suffix -ity alters the meaning into the quality of being popular (Oxford Dictionary, 2013).The derivational process of the new word popularity $(\mathrm{N})$ can be seen in the hierarchical structure which represents in tree diagram below:

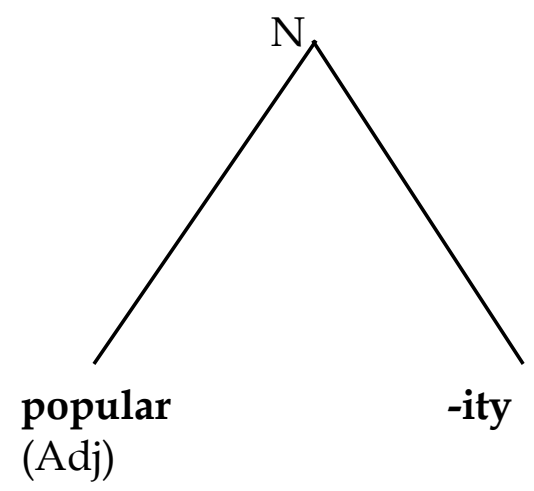

\section{Data 6}

...indicating very clear and purposeful end to the so-called 'awesome foursome's' combined charitable endeavours. (New Idea, P. 10)

In data 6, the word purposeful (Adj) can be categorized as derivational suffix. It can be seen that the word purposeful (Adj) consists of two morphemes such as purpose $(\mathrm{N})$ as free morpheme and suffix -ful as bound morpheme. Suffix -ful is attached to the base word purpose $(\mathrm{N})$ and creates a new word purposeful (Adj). The base word purpose $(\mathrm{N})$ the reason behind a goal that is made or created to 
be done so that the goal becomes a reality (Oxford Dictionary, 2013). The new word purposeful (Adj) a meaningful determination that has a goal that will be aimed at achieving a success (Oxford Dictionary, 2013. The derivational process of the word purposeful (Adj) can be seen in the hierarchical structure which represent in tree diagram below:

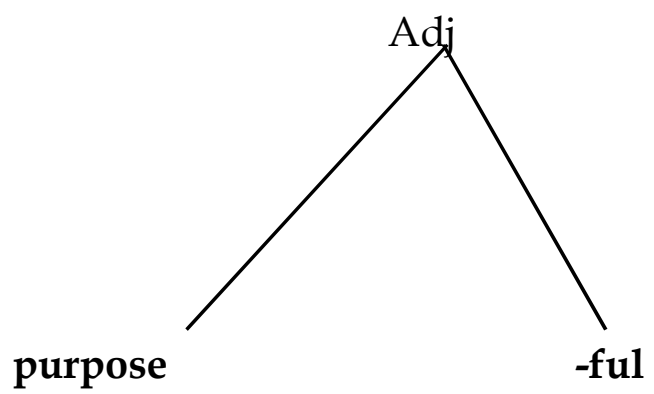

$(\mathrm{N})$

\section{Data 7}

A free budget planner that makes managing personal finance ridiculously simple. (New Idea, P. 63)

The word personal (Adj) in data 7 clearly contains suffix -al. The base word person $(\mathrm{N})$ (free morpheme) is attached by suffix -al (bound morpheme) becomes personality (Adj). Suffix -al causes the word class of the base change from noun to adjective. Therefore, suffix -al can be categorized as derivational suffix. The base word person $(\mathrm{N})$ a human being or known as an individual creature, but humans in general are social creatures because they cannot live alone and definitely need help from others (Oxford Dictionary, 2013). Then, suffix -al alters relating to influencing a person or not more than one person or a community or group (Oxford Dictionary, 2013). The derivational process of the word personal (Adj) can be seen in the hierarchical structure which represents in tree diagram below:

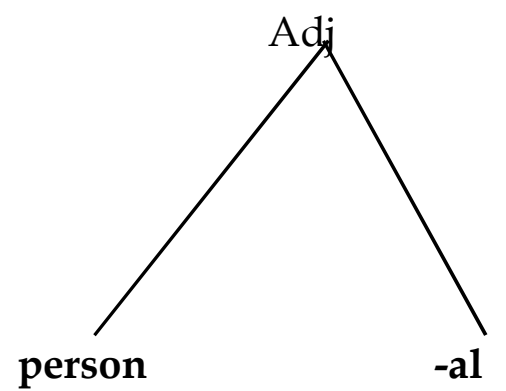

$(\mathrm{N})$

\section{Data 8}

...Virginia shares the identity of the mysterious walker and why she 
now feels he was an angel on the path.., (New Idea, P.79)

The word walker $(\mathrm{N})$ in the data 8 , can be classified as derivational suffix. Since, there is suffix-er (bound morpheme) that attach to the base word walk (V) (free morpheme) and make a new word walker $(\mathrm{N})$. The function of suffix-er is to change the meaning and also change the word class. The base word walk (V) its an activity carried out by living things to move from one place to another (Oxford Dictionary, 2013) and after adding suffix-er the meaning changes into actors or living beings who carry out an activity of moving from one place to another (Oxford Dictionary, 2013). The morphological process word walker $(\mathrm{N})$ can be seen in the tree diagram below:

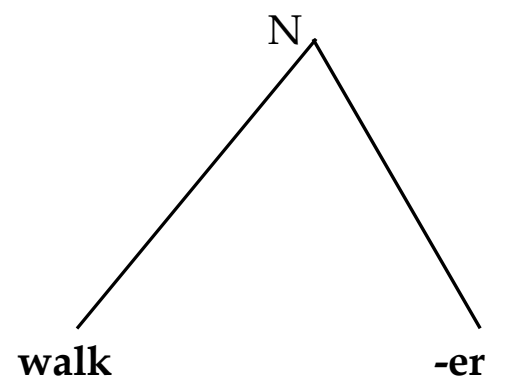

(V)

\section{Data 9}

..I am done. I dont want to be here." "I think that's our relationship done," Dannii said said sadly. (New Idea, P. 21)

The word sadly (Adv) is indicated as derivational suffix. The new word sadly (Adv) is derived from the base word sad (Adj). Suffix -ly is attached after the base word sad (Adj) become sadly (Adv). The word sadly (Adv) consist of two morphemes, they are sad (Adj) as a free morpheme and suffix -ly as a bound morpheme. The meaning of base word sad (Adj) is a person's emotional feelings that are shrouded in unhappiness that can lead to moodiness, gloom and tears (Oxford Dictionary, 2013) and suffix -ly alters the meaning into a feeling of sadness that a person feels because of a problem or something that can make their heart hurt (Oxford Dictionary, 2013). The morphological process of the word sadly (Adv) can be seen in the tree diagram below: 


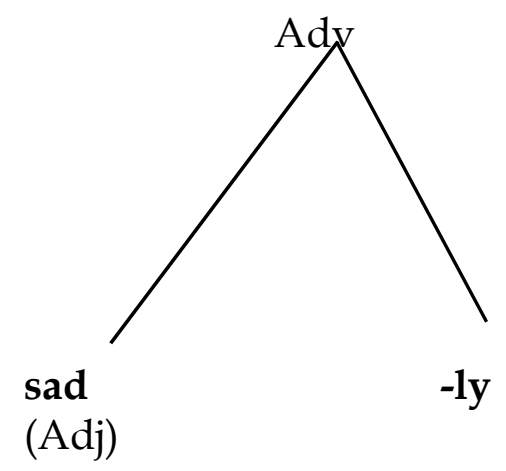

\section{Data 10}

... "You have done more to bring shame on the family than could ever have been imagined", (New Idea, P. 13)

In data 10, the word imagined (Adj) is indicated as derivational suffix. The new word imagined (Adj) is derived from the base word imagine (V). Derivational suffix-ed is attached to the base word imagine (V) become imagined (Adj). Suffix -ed change the word class of the base. The meaning of the word imagine $(\mathrm{V})$ is an activity that a person does by using his imagination to imagine something (Oxford Dictionary, 2013) and the new word imagined (Adj) means subjected to or affected by imagine (Oxford Dictionary, 2013). The morphological process of the word imagined (Adj) can be seen in the tree diagram below:

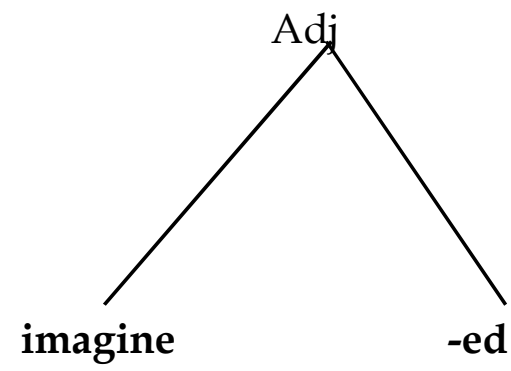

(V)

\section{CONCLUSION}

Based on the result of the study, this study found both types of derivational affixes which were derivational prefix and derivational suffix. There were 427 data that contained derivational affixes found in "New Idea" magazine. Derivational prefixes occurred in 52 words with percentage $12 \%$ and derivational suffixes occurred in 375 words with percentage $88 \%$ in the data source. It can be concluded that the most frequency data were derivational suffixes with the percentage $88 \%$ or 375 data of 427 data. Prefixes were found in data source such as prefix in-, un-, dis-, re-, ex-, en-, and pre-. Suffixes were found in data source such 
as suffix-hood, -ship, -ness, -ity, -ment,-less, -ful,-ic,-al,-er,-ly,-ion,-ish,ing and -ed.

\section{REFERENCES}

Finegan, E. (2008). Language: Its Structure and Use. (M. B. Walden, Ed.) USA: Michael Rosenberg.

Lestari, D. (2021). Directive Speech of Balinese Women: A Study of Sociolinguistics. Traverse: Journal of Language and Applied Linguistics.

Vol.2,

No.1. https://traverse.asia/index.php/traverse/article/download/11/1 $\underline{2}$

Lieber, R (2009). Introducing Morphology.The Edinburgh Building, Cambridge CB2 8RU, UK: United States of America by Cambridge University Press, New York.

Katamba, F. (1993). Morphology. London: Macmillan Press LTD.

McCarthy,Andrew Castairs. 2002. An Introduction to English Morphology. Edinberg University Press Ltd.

Dictionary, O. (2013). Oxford English Dictionary Mini Edition. Great Clarendon Street, Oxford, United Kingdom: Oxford University Press. 